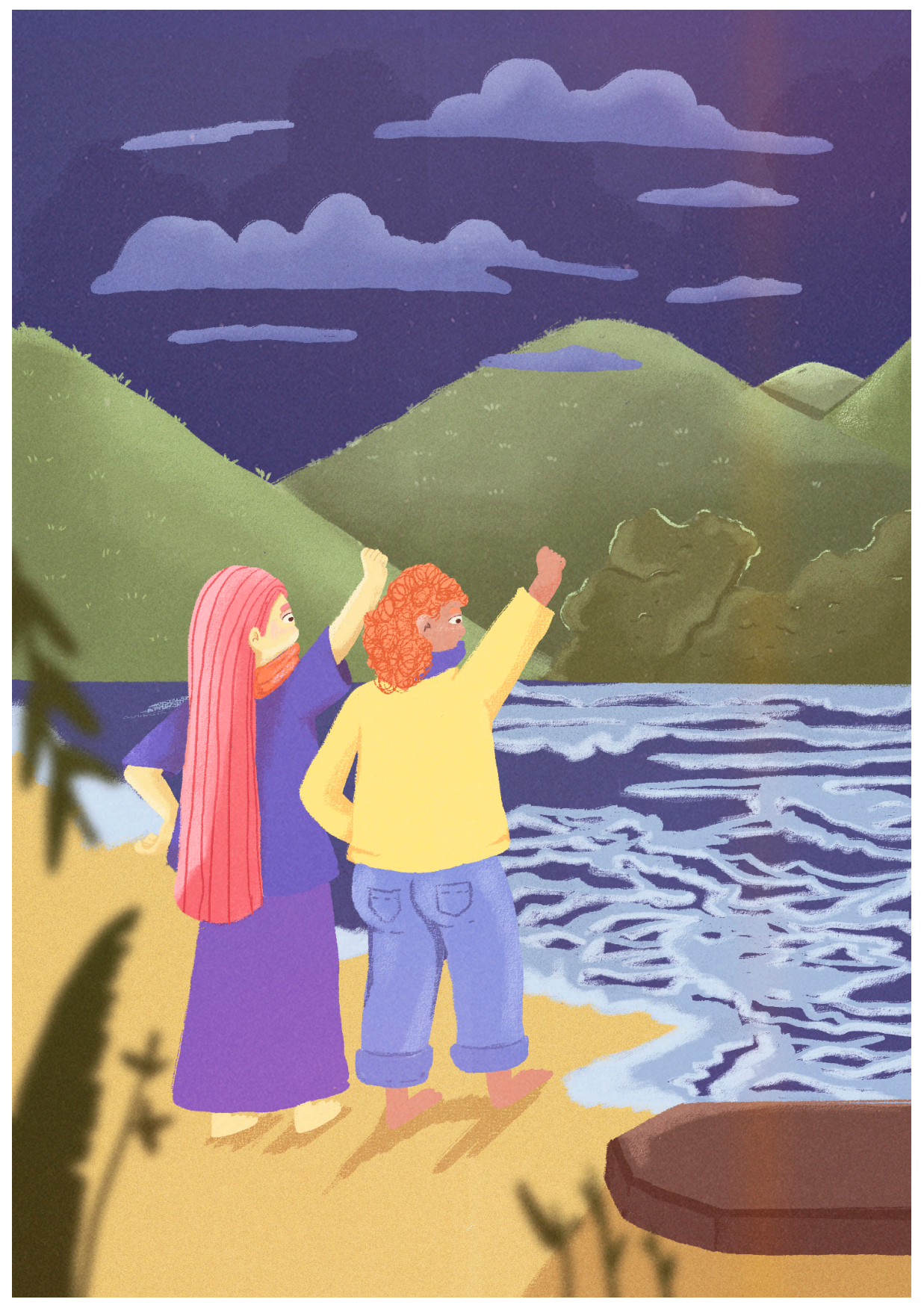




\section{The voices of those forgotten}

\section{Noor Al-lamee ${ }^{1}$}

\section{allameenoor@gmail.com}

During my degree, I completed a fieldwork project in Colombia; researching sexual violence amongst women, and the support and counselling services they received by community churches, specifically within the Caribbean Coast. The project took place in Monteria and Barranquilla, and I interviewed a total of 17 women, supported by pastors and trained psychologists in their recovery; post traumatic events. The aim was to understand the quality of support, how much it truly helped them and to gain a better understanding in the background of these women and the gross impact sexual violence had on their lives.

I heard a variety of stories, ones that I found particularly hard to digest and forget, during my time in Colombia and returning back to England. Their voices are with me always, describing the atrocities that armed groups inflicted upon them and the strength it has taken to continue with their lives. They were each, strong and

1 Fourth year Medical student at Southampton University, with an additional degree $(B S c)$ in International Health from the University of Leeds. 
beautiful women, that provided great insight into the capability of the human mind to overcome adversity. During my time in Colombia, I had the opportunity to travel around from North to South and truly fell in love with it's rich culture, the beauty of each city and the kindness exhibited by everyone I met.

As a coping mechanism, during the final day of the interviews after a series of emotional and tiresome days, I was finding it hard to sleep. I had the voices of each woman I had met, rushing through my mind and no way of understanding it. So, I began to write. It is called "The Voices of Those Forgotten", as their stories were one's the world have rarely heard before- but carry equal importance in highlighting the atrocities that happen to women all over the world. They require recognition, support and greater understanding. 
My story does not reach your international waters

Your news feeds

And media headlines

I am part of a forgotten nation

Hidden by the beauty of this land

Recognised as a traveller's hotspot

I am much more than a lonely planet

Tread carefully

Through the trenches of my broken heart

Mother Nature made this country rich and fertile

Yet forgot the very mothers that nurture this land

She spread seeds of vegetation that grew into fountains of trees

Lay sand for the Caribbean Sea to settle

And mountains for the world to see

Every inch more diverse than the next, a country with the beauties of an entire continent

Your passion, vibrancy and music shine through. 
Then, when you stop

To listen to the voices of those forgotten

You hear stories you cannot comprehend

Hidden under the glossy surface of the South American sun

We are the women that have been beaten

Burdened by the violence of men

Your war gave us shells, built walls where they should not be

Hardened our minds

Suppressed thoughts that were made to be free

Your evil made an evil in me

As you tortured and blinded all I could see

You silenced my rights

To fuel your fights

Stole my children to make generations unworthy

To manipulate minds and make soldiers of our youth

Rid them of a truth

That would liberate our land,

To serve your own hand 
In a war

So immature

Unsure

Of what you're truly fighting for

You turned a mother's heart into a coffin of her child

She was exiled

From the home, the very shelter that built your bones

Now you men, reply thank you mother

With the beating of your drum

Overflowing with rum

To numb

The voices of the women they should of become. 